\title{
Comparative study of the alkali-silica reaction (ASR) in granitic aggregates
}

\section{Estudio comparativo de la reacción álcali-sílice (RAS) en áridos graníticos}

\author{
A. Velasco-Torres ${ }^{1}$, P. Alaejos ${ }^{1}$, J. Soriano ${ }^{1}$
}

\begin{abstract}
The reaction between certain reactive components of aggregates (like opal and metaestable silica) and concrete pore solution is well documented. Nevertheless, in this study it has been shown that some aggregates, like granite, could develop a rapid or slow alkali-silica reaction (ASR) depending on the deleterious component involved.

Mortar bars were cast with two granitic aggregates extracted from concrete cores drilled in two Spanish Dams affected by ASR, being classified as granitic rocks. The main difference between them is the reactive component: microcrystalline quartz in one case and strained and microcracked quartz in the other case.

A petrographic examination was carried out in the mortar bars. Thin sections were cut and the alkalisilica gel was stained for an easier detection. Then, the thin sections were examinated with a stereomicroscope comparing the differences in the progress of the ASR for both aggregates.

It can be concluded that the main mechanism of formation and storage of gel is associated to the microcracks instead of the subgrain boundaries.
\end{abstract}

Key words: alkali-silica reaction, mortars, granite, quartz, slow reacting and rapid-reacting aggregates.

\section{RESUMEN}

La reacción entre los componentes de la fase intersticial del hormigón y áridos con minerales como el ópalo o la sílice metaestable, se encuentra bien documentada. Sin embargo, en este estudio, se ha detectado que dentro de un mismo tipo de roca, como es el granito, puede haber diferencias en el tipo de reacción (lenta o rápida) dependiendo del componente reactivo que aparezca en la misma.

Se han fabricado barras de mortero con los áridos extraídos de dos presas españolas afectadas por la reacción álcali-sílice. Estos áridos son rocas graníticas y la diferencia entre ambos reside en que una de las muestras contiene cuarzo microcristalino como componente reactivo y, la otra, cuarzo deformado.

Mediante el estudio petrográfico de barras de mortero y el teñido del gel álcali-sílice se ha podido observar la evolución y progreso de la reacción para cada uno de los componentes reactivos.

La principal conclusión que se puede extraer de este estudio es que la formación y almacenamiento del gel se asocia a microfracturas en lugar de a límites de grano. lenta.

Palabras clave: reacción álcali-silica, morteros, granito, cuarzo, agregados de reacción rápida y de reacción

\section{Introduction}

Stanton studied in 1940 the Parker Davis dam in California, which showed cracking and expansion. As a result of his study, Stanton concluded that the damage was due to an interaction between aggregates (altered andesites and rhyolites) and the alkalis of the concrete pore solution (Poole, 1992).

Since Stanton's discovery the knowledge of alkali-aggregate reaction (AAR) has progressed but still

\footnotetext{
1 CEDEX-Laboratorio Central de Estructuras y Materiales, Alfonso XII, 3 y 5, 28014, Madrid. Email: avelasco@cedex.es, palaejos@cedex.es, jsoriano@cedex.es
} 
some aspects should be investigated, like the development of faster and more reliable methods to evaluate the potential reactivity of aggregates (Poole, 1992; Wigum, 1995a).

In alcali-silica reactions (ASR) a deleterious chemical reaction takes place between certain reactive siliceous minerals in aggregates and alkali ions in the concrete pore solution. This reaction produces a gel, which imbibes water and expands when it is exposed to moisture, cracking the aggregates and the cement paste. Depending on the rate of reaction, there is a rapid ASR due to aggregates containing metaestable or microcrystalline quartz, and a slow/late ASR, when aggregates contain strained or microcracked quartz.

Traditionally the potential reactivity of rocks has been evaluated according to their geological term, and granitic rocks are commonly classified as innocuous. Sometimes they appear as low-reactivity aggregates (Lorenzi et al., 2006) if there is strained (Wigum, 1995b) or microcrystalline quartz in their composition (Grattan-Bellew, 1992; Wigum \& French, 1996). The attack of the quartz by the concrete pore solution takes place mainly on the surface, or through existing cracks or microstructural alterations. Thus, a high concentration of dislocations, microcracks or stress due to the crystal deformation, could enhance the quartz reactivity (GrattanBellew, 1992; Peng-Xiang, 2004 y Ponce \& Batic, 2006). Also, polygonization of crystals to form microcrystalline quartz could cause the reaction.

\section{Research significance}

In this investigation it has been carried out a comparative study of the development of slow and rapid alkali-silica reaction in granitic aggregates. The aims of this investigation were:

- To study how alkalis in concrete pore solution penetrate into aggregates, for both slow- and rapidreacting aggregates.

- To observe the evolution of the alkali-silica gel formed in both cases.

- To analyse the influence of the feldspars in the progress of the ASR.

The final goal was to contribute to a better understanding of the slow/late reaction, less studied than the rapid one, and much more frequent in the Spanish dams.

Knowing more about this kind of reaction could allow us to develop new and more accurate methods for the detection of slow-reacting aggregates.

\section{Methodology}

Two granitic aggregates were selected, extracted from the concrete of two Spanish dams affected by ASR. One of them showed microcrystalline quartz as reactive component and the second one had strained and microcracked quartz without presence of any other reactive component.

Both aggregates were tested according to the Spanish standard (UNE 146508 EX, similar to ASTM C 1260) to evaluate the potential reactivity. Once the expansion of the mortar bars was measured, thin sections were made according to ASTM C 85604 . The process to make these thin sections is similar to rocks, but using oil as refrigerant agent instead of water, to avoid alteration of the mortar.

The thin sections were stained (they are immersed in a saturated solution of Copper-Ammonium Sulphate during 72 hours) following Ponce \& Batic (2006), Poole et al. (1988) and St John et al. (1998) to facilitate the identification of the alkali-silica gel.

Afterwards the stained fragment is glued on a microscope slide and is polished to have a section around $30 \mu \mathrm{m}$ thick. With the staining process the gel formed by the ASR is dyed blue and is easily detectable with a stereomicroscope. The polarized microscope allows us to identify the reactive components and the reaction development.

\section{Characterization of the studied aggregates}

\section{Petrographic examination}

Two different granitic aggregates extracted from two dams affected by the ASR were studied.

The first one (Aggregate A) is classified as porfidic biotite granodiorite (Streckeisen, 1974). This granodiorite is quartz rich and fine to medium grain sized (Fig. 1-A and Fig. 1-B). The main minerals in this rock are:

Quartz (41\%): Anhedral shape and hard strained with undulatory extinction, polygonised. The rock shows microcrystalline quartz in the subgrain boundaries formed by recrystallization (Fig. 1-C and Fig. 1-D). Because of the detection of the microcrystalline quartz in this rock, it was quantified in accordance with RILEM (2003).

Plagioclase feldspar (30\%): They have subhedral or anhedral shape crystals, some of them zoned and others are multiple twinned. 

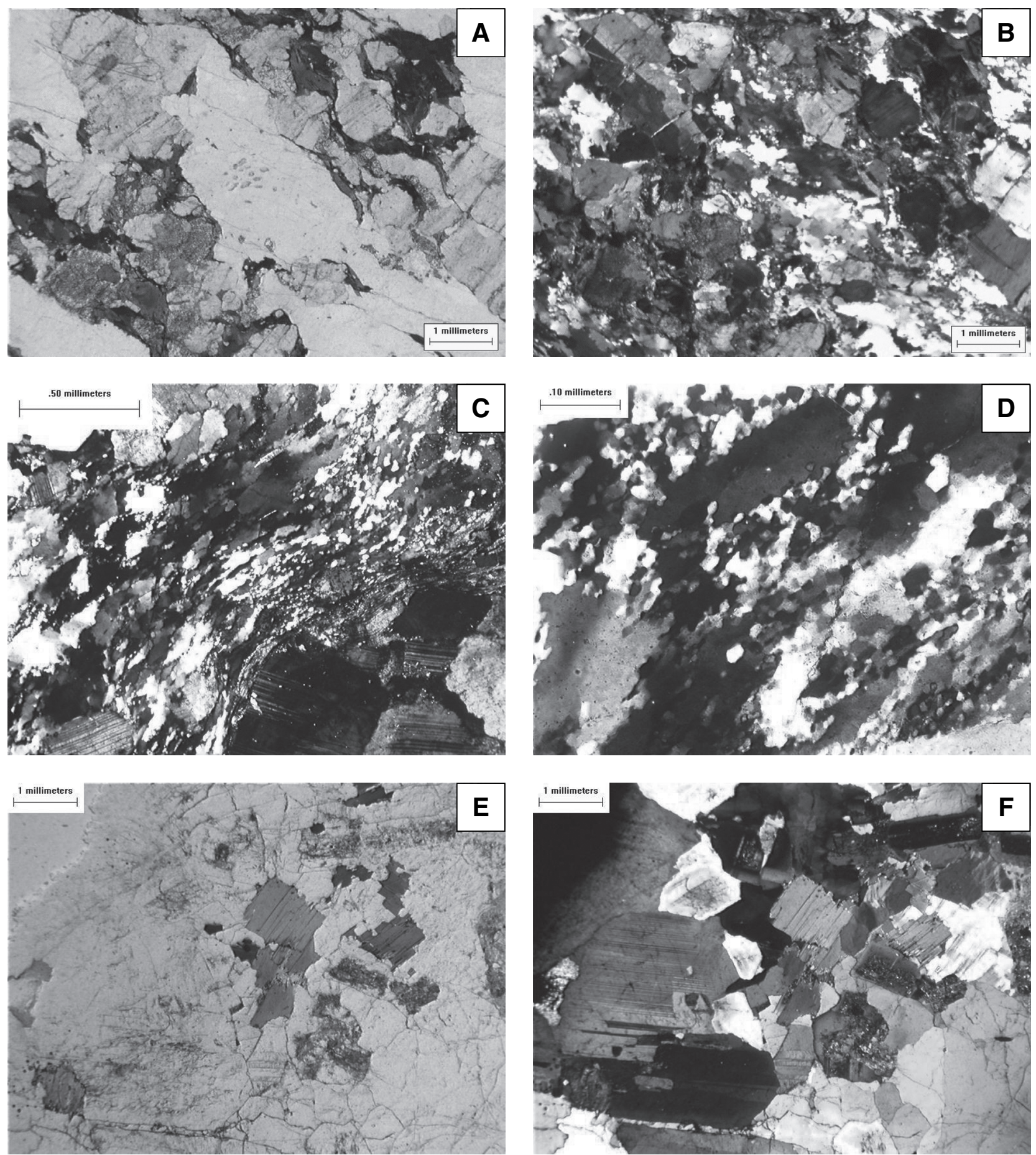

Fig. 1.-A) Granodiorite. PPL; B) Granodiorite. XPL; C) Anhedral Quartz crystals, strongly strained and recrystallizated. XPL; D) Detail of the microcrystalline quartz. XPL; E) Monzogranite. PPL; F) Monzogranite. XPL. 
Potassium-rich feldspar (12\%): Perthitic texture with plagioclase feldspar, biotite and sometimes quartz inside.

Biotite (17\%): It shows tabular crystals parallel to foliation. Some of them show deformation as the nearby quartz (Fig. 1-C).

The second sample (Aggregate $\mathrm{B}$ ) is a monzogranite Streckeisen (1974) (Fig. 1-E and Fig. 1-F). The main minerals are:

Quartz (28\%): Quartz appears as subhedral, subrounded crystals with microcracking and $25^{\circ}$ undulatory extinction angle (Dolar-Mantuani, 1981) (Fig. 2-A and Fig. 2-B). Some crystals show plagioclase feldspar and biotite inside.

Plagioclase feldspar (39\%): It shows subhedral crystals and multiple twinned and zoned crystals.

Potassium-rich feldspar (23\%): It shows Perthitic, subhedral crystals with cross-hatched and Carlsbad twinning.

Biotite (10\%): It appears as subhedral crystals and sometimes they form microgranular agglomerates.

\section{Quantification of the microcrystalline Quartz in the Aggregate $A$}

The quantification of the microcrystalline quartz was carried out according to the RILEM method. An important amount (8\%) of microcrystalline quartz was found in the petrographic analysis of the Aggregate A, which explains the ASR affecting the dam and its deterioration (Table 1).

It has not been detected microcrystalline quartz in Aggregate B and so, its reactivity is only caused by the microcracked and strained quartz present in the monzogranite.

Table 1.-Results of the point counting method

\begin{tabular}{lcc}
\hline \multicolumn{3}{c}{ SAMPLE A 2-4 } \\
\hline \multicolumn{1}{c}{ Point counting } & Points & Percentage \\
\hline Resin & 989 & \\
Coarse grained quartz & 222 & 13 \\
Fine grained quartz & 53 & 3 \\
Microcrystalline quartz & 137 & 8 \\
Potassium-rich feldspar & 429 & 25 \\
Plagioclase feldspar & 348 & 20 \\
Biotite & 148 & 9 \\
Sericite & 245 & 14 \\
Chlorite & 65 & 4 \\
Moscovite & 68 & 4 \\
Effective points & 1,715 & 100 \\
\hline
\end{tabular}

\section{Results from the petrographic examination of the mortar bars}

Figure 3 shows the results of the accelerated mortar bars test. Aggregate A just exceeded the expansion limit $(0.20 \%)$ at 28 days, whereas Aggregate B showed an expansion of $0.085 \%$ at 28 days and exceeded the limit at 75 days.

Therefore, the Aggregate A is classified as alkali reactive according to the method criteria and the Aggregate B is classified as innocuous, although indeed the dam was affected by ASR.

\section{Slow-reacting aggregates}

In the slow-reacting aggregates the concrete pore solution penetrates into the quartz through two main access channels: subgrain boundaries or previous microcracks in the crystals. The difference between both ways is observed with the polarized microscope. There is undulatory extinction in the first case (Fig. 2-C and Fig. 2-D) and not in the second one (Fig. 2-E and Fig. 2-F), which instead shows small microcracks. The production of gel is higher in the microcracked particles (Fig. 4-A) than in those with strained quartz (Fig. 4-B) at the same treatment age (180 days). These results can help to explain the bad correlation between the potential reactivity and the UEA (undulatory extinction angle), usually mentioned in the bibliography.

A partial dissolution of the strained quartz can be found in the zones where the polygonization is visible. The dissolution of the quartz appears where the presence of dislocations and previous microcracks is more marked (Fig. 4-C).

Alkali-silica gel is formed inside the aggregate when the silica from the strained quartz is dissolved. The presence of alkali-silica gel starts to be visible after 90 days of treatment (Fig. 2-C, Fig. 2-D and Fig. 4-D), just when the expansion limit is exceeded.

When the pore solution attack and the gel generation continues, it begins to fill the concrete micropores cracking the cement paste and cracks spread out (Fig. 4-E).

If the bars are stored for a longer time, more gel can be observed in the aggregate particles, especially in those with previous cracks (Fig. 4-F, sample with 365 days and an expansion of $0.49 \%$ ). The partial dissolution of zones of the quartz (those 

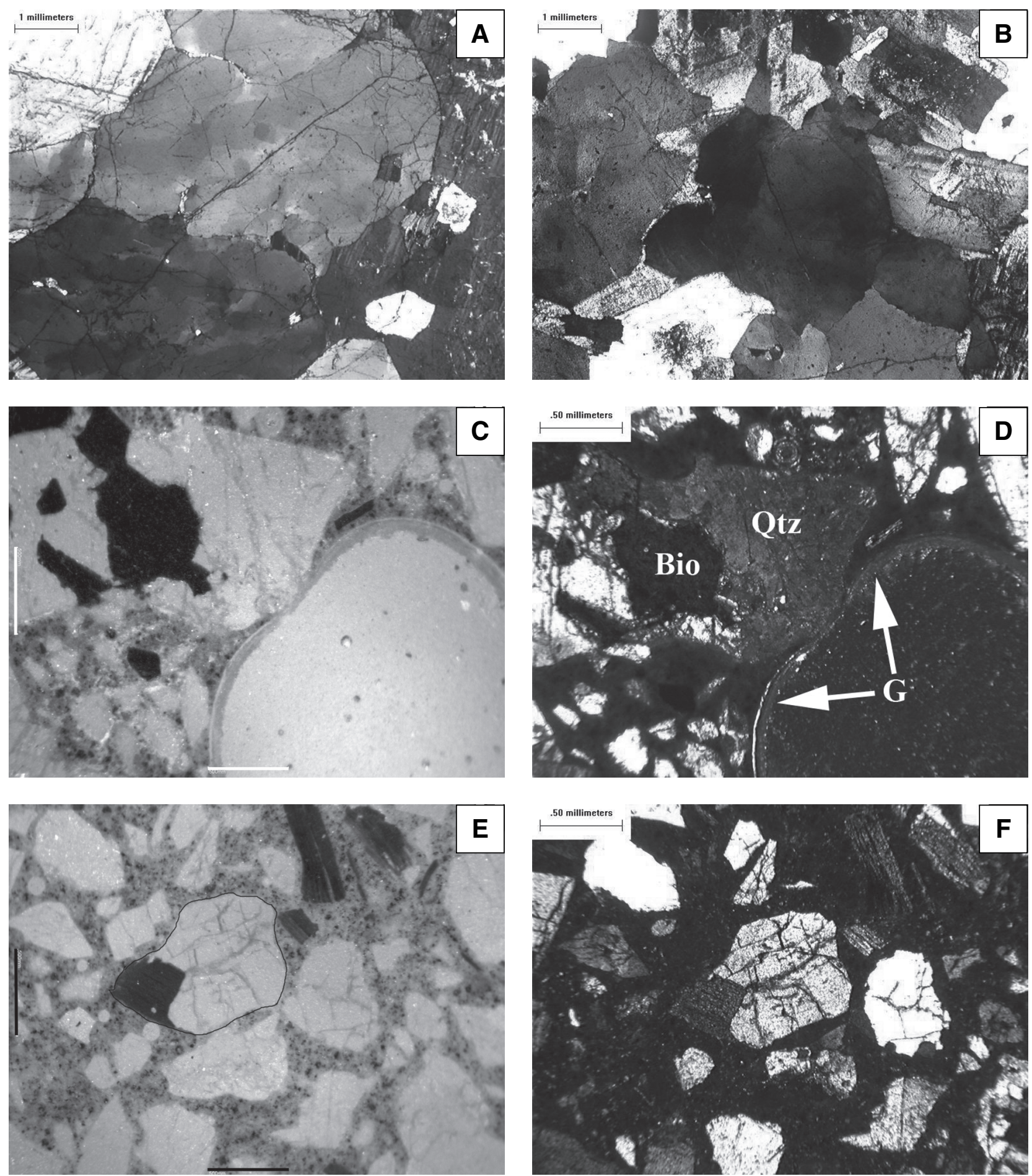

Fig. 2.-A) Strained and microcracked Quartz. XPL; B) Strained Quartz. XPL; C) Granitic particle. The gel is accumulated parallel to the direction of the undulatory extinction and in the pore near the aggregate (blue colour in the image) Scale bar $=500 \mu \mathrm{m}$. RL. Age $=90$ days; D) Undulatory extinction in a quartz crystal. The storage of the gel coincides with the subgrain boundaries. XPL; E) Granitic particle. The gel fills the quartz microcracks. Scale bar $=500 \mu \mathrm{m}$. RL. Age $=90$ days; F) Quartz crystal from a granitic particle with parallel extinction. XPL. 


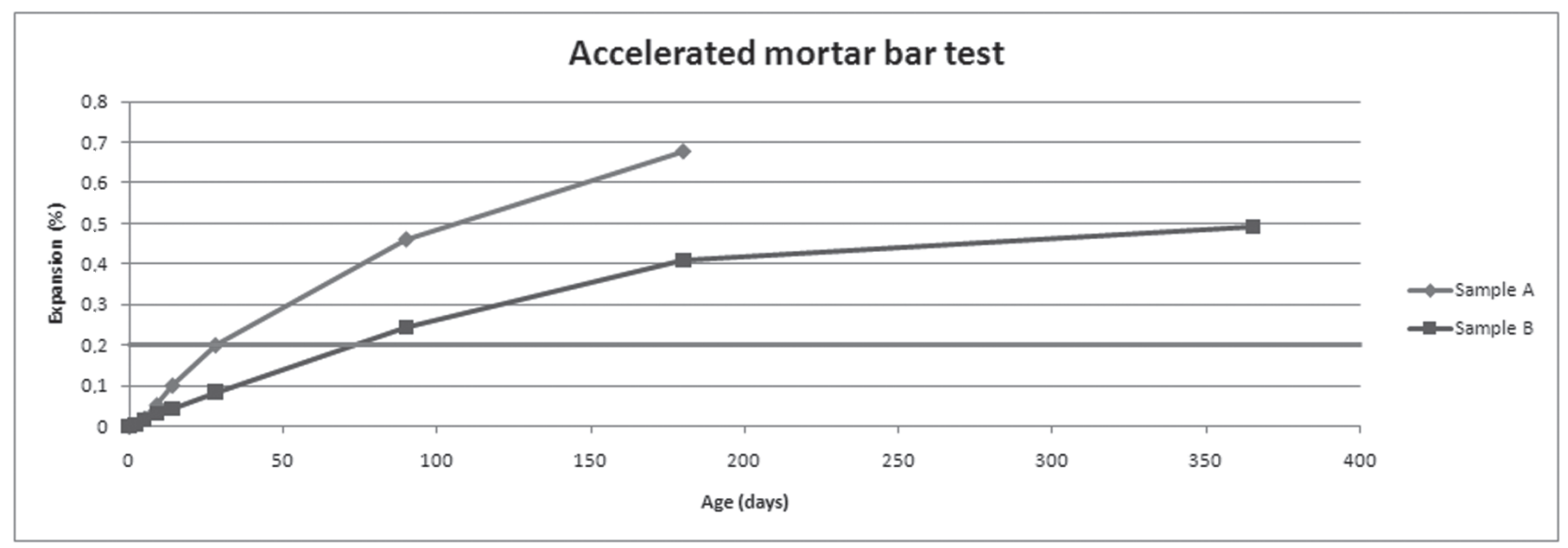

Fig. 3.-Results from the accelerated mortar bar test.

with defects in the crystal lattice) is much more frequent at later stages and the pores of the paste contain a huge amount of gel. The aggregates and the cement paste cracking is also much more intense (Fig. 5-A).

\section{Rapid-reacting aggregates}

The rapid-reacting granite studied in this research shows a similar slow/late reaction than the previously described, developing in the subgrain boundaries and especially in the microcracks. But also a quicker reaction can be observed, which is concentrated in the microcrystalline quartz.

The evolution of the reaction in the rapid-reacting aggregates is as follows:

The concrete pore solution infiltrates into the particle and it advances from the surface of the particle surrounding the microcrystals. The microcrystalline quartz shows a rapid dissolution and large zones inside the particles are dissolved (Fig. 5-B).

Afterwards, the alkali-silica gel is formed inside the aggregate and flows to the paste pores around it (Fig. 5-C).

The aggregates dissolution in this kind of aggregates is obvious rapidly and in a short period of time the mortar pores have a huge amount of gel inside. The microcracking of the aggregates, as well as the cement paste, is more intense at earlier stages (Fig. 5-D, Fig. 5-E and Fig. 5-F, age: 41 days). This is in agreement with the high and quick expansion registered in the accelerated mortar bar test $(0.274 \%$ in 41 days).

\section{Role of the feldspars}

The contribution of the feldspars to the ASR was observed in the granitic rocks studied. So, there are particles with a large amount of gel just where the quartz crystal is in contact with the plagioclase feldspar (Fig. 6-A and Fig. 6-B) or potassium-rich feldspar (Fig. 6-C and Fig. 6-D).

This effect could be more accused if the granite contains mirmekite or perthite structures, like the one studied.

\section{Conclusions}

Some international recommendations about ASR classify the reactivity of rocks according to their geological term, but the same kind of rock could be slow- or rapid-reacting aggregate depending on its components and/or its microstructural characteristics.

At the moment, there are no methods reliable enough to evaluate the reactivity of slow-reacting aggregates, which are the most frequent in Spain.

In this study a comparative study of two granitic rocks extracted from two ASR affected dams has been carried out. One of them is a slow-reacting aggregate, with strained and microcracked quartz as reactive component, and the other one is a rapidreacting aggregate, with microcrystalline quartz as reactive component.

In rapid-reacting aggregates, the attack by the concrete pore solution begins to dissolve the zones of microcrystalline quartz just in contact with the cement paste. This generates a huge amount of gel, 

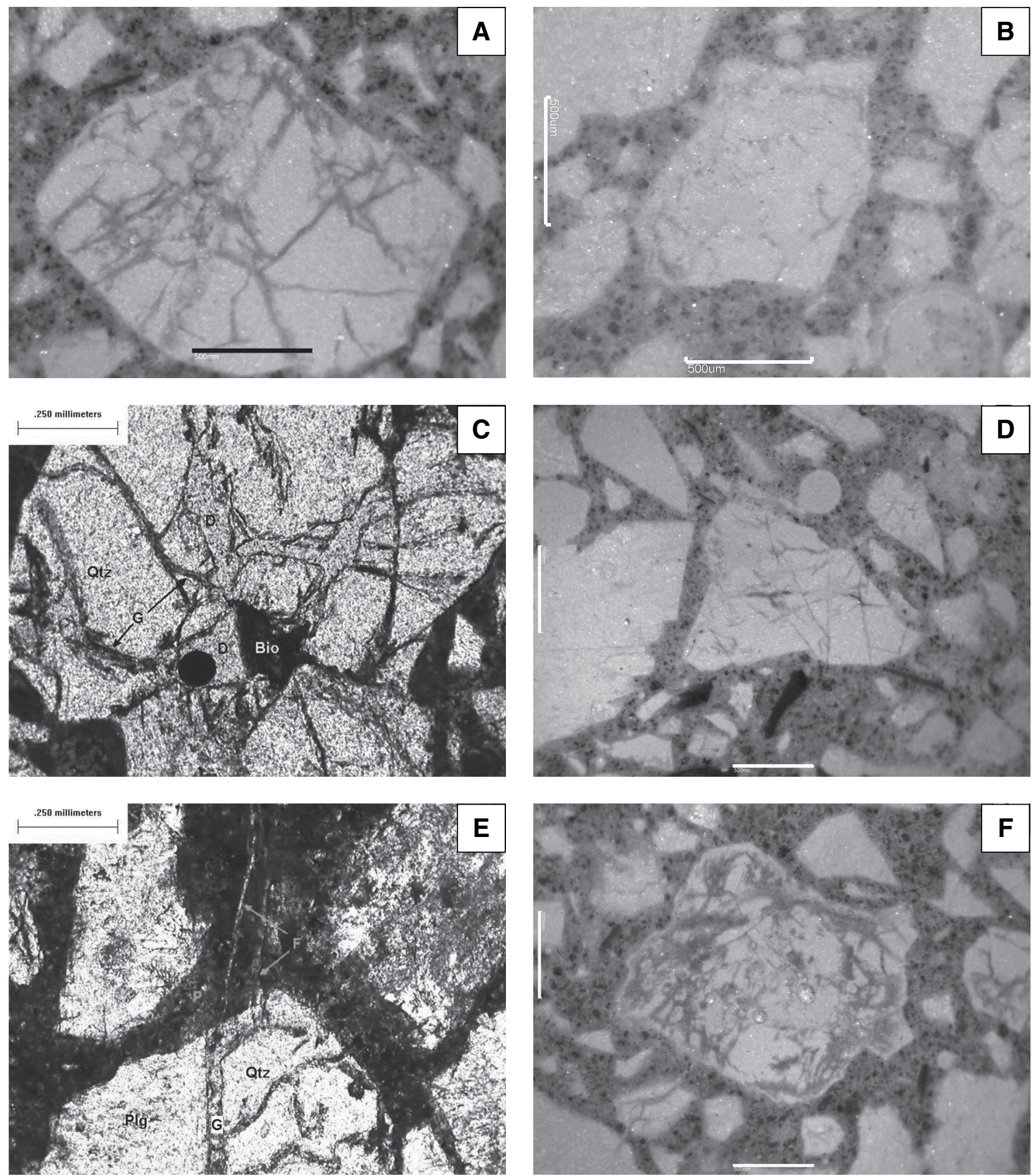

Fig. 4.-A) Quartz particle with alkali-silica gel inside it. The presence of this gel in the microcracked particle is clearer than in next particle with strained quartz (photo on the right). Scale bar $=500 \mu \mathrm{m}$. RL. Age $=180$ days; B) Quartz particle with a little amount of alkali-silica gel. Scale bar $=500 \mu \mathrm{m}$. RL. Age $=180$ days; C) Granitic particle. The dissolution zones and the alkali-silica gel deposits are clearly visible $(Q t z=$ quartz; Bio = biotite; $G=$ alkali-silica gel y $D=$ dissolution zone). PPL; D) Quartz particle. Particle size: $1.5 \mathrm{~mm}$. Scale bar $=500 \mu \mathrm{m}$. RL. Age $=90$ days; F) Microcracks $(F)$ begin to appear in the cement paste $(P)$. The gel fills the microcracks (blue colour in the image). PPL; F) Quartz particle with a huge amount of alkali-silica gel inside it. Scale bar $=500 \mu \mathrm{m}$. RL. Age $=365$ days . 

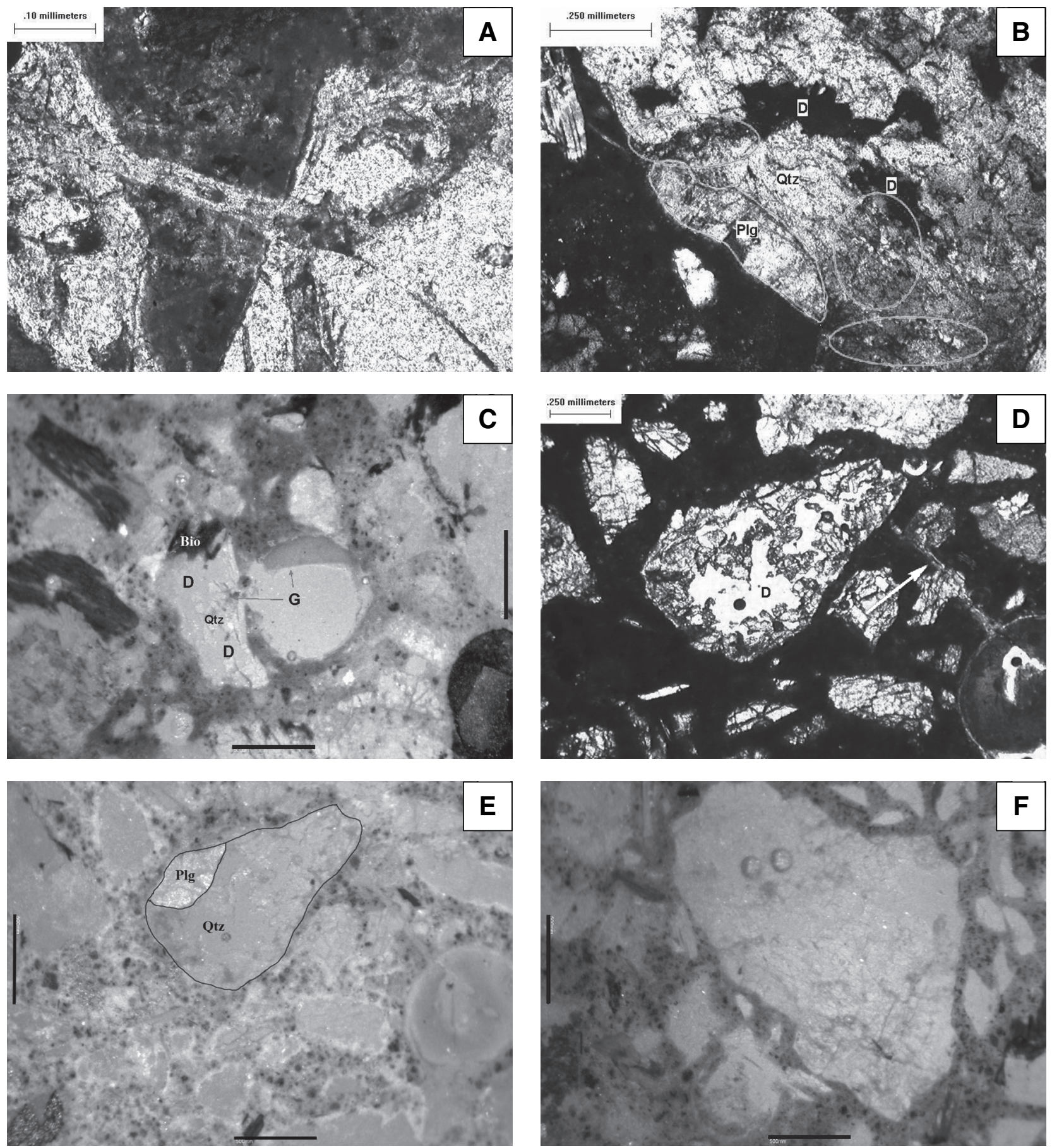

Fig. 5.-A) Microcrack filled of alkali-silica gel (blue colour in the image). The microcrack is perpendicular to the particle surface and affects the cement paste and a second aggregate near the first one. PPL; B) Granitic particle. An accumulation of quartz crystals can be distinguished in the image. Crystal size $=50 \mu \mathrm{m}$ (red ellipses in the image). The dissolution appears in the zones with microcrystalline quartz. Plg = plagioclase feldspar; Qtz = quartz y D = Dissolution zone; C) Granitic fragment. The alkali-silica gel (blue colour in the image) fills the surrounding cement paste and partly a pore near the particle. The quartz crystal is partially dissolved (D) by the mortar bar test solution. Scale bar $=500 \mu \mathrm{m}$. RL. Age $=41$ days; D) Granitic particle. The quartz crystal is partially dissolved (D) by the mortar bar test solution. The red arrow shows a microcrack which begins in the particle and goes through the cement paste and two other particles to a near pore, partly filled by the alkali-silica gel; E) Granitic particle. The alkali-silica gel (blue colour in the image) appears in the surrounding cement paste, also inside the particle and fills partly a pore near the particle. Scale bar $=500 \mu \mathrm{m}$. RL. Age $=180$ days; F) Granitic particle. The alkali-silica gel (blue colour in the image) fills some microcracks inside the particle and the surrounding cement paste. Scale bar $=500 \mu \mathrm{m}$. RL. Age $=41$ days. 



Fig. 6.-A) Granitic fragment. The plagioclase feldspar remains unaltered but on its surface could see an important amount of alkalisilica gel. Scale bar $=500 \mu \mathrm{m}$. RL. Age $=180$ days; B) The same fragment of the previous image. The alkali-silica gel is concentrated in the intercrystalline surface (Plg = plagioclase feldspar; $\mathrm{Qtz}=$ quartz y $\mathrm{G}=$ gel). PPL; C) Granitic fragment. The quartz is strongly strained and microcracked. It has alkali-silica inside (blue colour in the image). Scale bar $=500$. RL. Age $=365$ days; $D$ ) The alkali-silica gel is accumulated on the intercrystalline surface, between quartz and potassium-rich feldspar (Fto $\mathrm{K}=$ potassium-rich feldspar; $\mathrm{Qtz}=$ quartz y $\mathrm{D}=$ dissolution zones).

which is accumulated mainly in the surrounding paste in a short period of time. Additionally, there is also a slow/late reaction, originated by the strained or microcracked quartz.

In slow-reacting aggregates the concrete pore solution enters slowly inside the aggregate mainly through the microcracks and to a less extent through the subgrain boundaries. The cracking system is filled by the expansive gel and in the junction of different microcracks may appear silica dissolution.

The described mechanism explains why the correlations between UEA and the aggregate reactivity does not give good results in these kind of aggregates, because the main mechanism of formation and storage of gel is associated to the microcracks instead of the subgrain boundaries.

\section{ACKNOWLEDGMENTS}

The authors thank to the Dirección General del Agua (Ministerio de Medio Ambiente) the financial support and the opportunity to have samples from real affected dams to develop this investigation.

Also, the authors thank to the Ministerio de Ciencia e Innovación the financial support in the project "Desarrollo de un sistema integrado para la medida de estructuras de hormigón con problemas expansivos (DAMA)".

The authors thank División de Durabilidad del Hormigón y la División de Mineralogía y Petrología del Laboratorio Central de Estructuras y Materiales del CEDEX the technical support in the investigation. 


\section{References}

Dolar-Mantuani, L.M.M. (1981). Undulatory extintion in quartz used for identifying potentially alkali-reactive rocks. Proceedings of Conference on Alkali-Aggregate Reaction in Concrete. Pretoria. Surafrica. Paper S252/36.

Grattan-Bellew, P.E. (1992). Microcristalline quartz, undulatory extinction and the alkali-silica reaction. Proceedings of the $9^{\text {th }}$ international conference on alkali-aggregate reaction in concrete. 383-394.

Lorenzi, G.; Jensen, J.; Wigum, B.; Sibbick, R.; Haugen, M.; Guédon, S. \& Åkesson, U. (2006). Petrographic atlas of the potentially alkali-reactive rocks in Europe. Profesional paper N. 302. Geological Survey of Belgium. Bruselas, Bélgica. 63 pp.

Peng-Xiang, L. \& Hua-Quan, Y. (2004). Research on the activity for granite aggregate. Proceedings of the $12^{\text {th }}$ international conference on alkali-aggregate reaction in concrete. $355-361$.

Ponce, J.M. \& Batic, O.R. (2006). Different manifestations of the alkali-silica reaction in concrete according to the reaction kinetics of the reactive aggregate. Cement and Concrete Research, 36: 1148-1156. doi:10.1016/j.cemconres.2005.12.022

Poole, A.B.; McLachlan, A. \& Ellis, D.J. (1988). A simple staining technique for the identification of alkalisilica gel in concrete and aggregate. Cement and Contrete Research, 18: 116-120.
RILEM (2003). Recommended test method AAR-1. Detection of potential alkali reactivity of aggregates. Petrographic method. Materials and Structures, 36: 480-496. doi:10.1007/BF02481528

St John, D.A.; Poole, A.W. \& Sims, I. (1998). Concrete petrography. A handbook of investigative techniques. Elsevier Butterworth-Heinemann, Oxford, 488 pp.

Streckeisen, A.L. (1974). Classification and Nomenclature of Plutonic Rocks. Recommendations of the IUGS Subcommission on the Systematics of Igneous Rocks. Geologische Rundschau. Internationale Zeitschrift für Geologie, 63: 773-785.

Wigum, B.J. (1995a). Alkali-Aggregate reactions in concrete. Properties, classification and testing of Norwegian cataclastic rocks. $\mathrm{PhD}$ Thesis. University of Trondheim, $221 \mathrm{pp}$.

Wigum, B.J. (1995b). Examination of microstructural features of Norwegian cataclastic rocks and their use for predicting the alkali-reactivity in concrete. Engineering Geology, 40: 195-214. doi:10.1016/0013-7952(95)00044-5

Wigum, B.J. \& French, W.J. (1996). Sequential examination of slowly expanding alkali-reactive aggregates in accelerated mortar bar testing. Magazine of Concrete Research, 48: 281-292. doi:10.1680/macr.1996.48.177.281

Recibido el 16 de noviembre de 2009 Aceptado el 17 de febrero de 2010 Publicado online el 11 de mayo de 2010 